\title{
O verde da economia no campo: desafios à pesquisa e às políticas públicas para a promoção da saúde no avanço da modernização agrícola
}

\author{
The green rural economy: challenges to research \\ and to public health policies posed by agricultural modernization
}

Raquel Maria Rigotto ${ }^{1}$

Fernando Ferreira Carneiro ${ }^{2}$

Alice Maria Correia Pequeno Marinho ${ }^{3}$

Mayara Melo Rocha ${ }^{1}$

Marcelo José Monteiro Ferreira ${ }^{1}$

Vanira Matos Pessoa ${ }^{1}$

Ana Cláudia de Araújo Teixeira ${ }^{1}$

Maria de Lourdes Vicente da Silva ${ }^{1}$

Lara de Queiroz Viana Braga ${ }^{1}$

Maiana Maia Teixeira ${ }^{1}$

\footnotetext{
${ }^{1}$ Núcleo Tramas,

Departamento de Saúde Comunitária, Centro de Ciências da Saúde, Universidade Federal do Ceará. Rua Prof. Costa Mendes 1608/5 , Rodolfo Teófilo. 60431-970 Fortaleza CE. ntramas.ufc@gmail.com ${ }^{2}$ Departamento de Saúde Coletiva, Universidade de Brasília

${ }^{3}$ Escola de Saúde Pública do Ceará
}

\begin{abstract}
In this paper, we ask ourselves who should, can and has the will to promote health in the rural zone today. The fields of science and public policy were chosen as our primary focus of dialogue conducted from the perspective of the right to health and a healthy environment. Seven lessons emerged: (1) in addition to the surveillance of isolated chemical risks, the relation between agrochemicals and health should be investigated in the context of conservative agricultural modernization; (2) it is mandatory and urgent to discover the health problems related to the use of agrochemicals; (3) the State has been successful in its support of agribusiness, but highly inefficient at enforcing policies to safeguard social rights; (4) sectors of society linked to rural organizations have played an important role in the public policies combating agrochemicals and protecting health; (5) studies must help deconstruct the myths surrounding the Green Revolution model; (6) we are faced with the challenge of contributing to the construction of an emerging scientific paradigm founded on an ethical-political commitment to the most vulnerable social elements; (7) rural communities are creating agro-ecological alternatives for life in semiarid areas.
\end{abstract}

Key words Agricultural modernization, Public policies and society, Research, Health promotion, Health-work-environment
Resumo Neste ensaio, é feita a pergunta de quem deve, pode e quer promover a saúde no campo hoje. Foi eleito, prioritariamente, o campo da ciência e o das políticas públicas como foco de diálogo. Configurou-se oito lições aprendidas sob a perspectiva dos direitos à saúde a um ambiente saudável, aqui compartilhadas: (1) para além de um risco químico isolado, a relação entre agrotóxicos e saúde deve ser estudada no contexto da modernização agrícola conservadora; (2) é necessário e urgente que se proceda ao desvelamento dos agravos à saúde relacionados aos agrotóxicos; (3) o Estado tem tido significativa eficácia no apoio ao agronegócio e significativa ineficácia nas politicas sociais de garantia de direitos dos trabalhadores e da população; (4) setores da sociedade ligados às organizações do campo vêm desempenhando importante papel na política pública de combate aos agrotóxicos e de proteção da saúde; (5) é importante que os estudos contribuam para a desconstrução dos mitos que sustentam o modelo da Revolução Verde; (6) se está diante do desafio de contribuir na construção de um paradigma emergente de ciência, fundado no compromisso ético-político com os mais vulneráveis; (7) comunidades camponesas vêm construindo alternativas agroecológicas de vida no semiárido.

Palavras-chave Modernização agrícola, Políticas públicas e sociedade, Pesquisa, Promoção da saúde, Saúde-trabalho-ambiente 


\section{Introdução}

Em cerca de meio século de hegemonia do modelo de desenvolvimento para o campo difundido a partir da Revolução Verde - expansão de monocultivos por grandes empresas agroindustriais, mecanização da produção, intensiva utilização de insumos químicos, incorporação da biotecnologia - ainda são pouco visíveis, do ponto de vista científico, as implicações para as questões fundiária, ambiental, cultural e de saúde. De acordo com Miranda ${ }^{1}$, se a produção mundial de grãos por hectare duplicou entre 1950 e 1980, o consumo de fertilizantes químicos saltou de 4 para 150 milhões de toneladas em 60 anos do século XX. O Planeta segue longe da segurança alimentar, convivendo com 1 bilhão de pessoas com algum tipo de desnutrição. No Brasil, somente entre os anos 2005 a 2011, a utilização de agrotóxicos dobrou, transformando o país no maior mercado consumidor desses tipos de venenos do mundo.

O que significaria agora a nova estratégia discursiva da Economia Verde? Em que medida trará instrumentos e consensos para a "erradicação da pobreza e a governança para a sustentabilidade do planeta"? Como vem incidindo sobre territórios de países periféricos, já subordinados à reprimarização de nossas economias para produzir commodities de alto impacto ambiental, social e cultural? O informe das Nações Unidas sobre Segurança Alimentar, por exemplo, afirma a relação entre a crise mundial dos preços dos alimentos e o incremento na produção dos supostamente "limpos" agrocombustíveis, aos quais temos dedicado boa parte de nossas terras agricultáveis, da água e do trabalho agrícola.

Neste cenário político e econômico hegemônico no plano mundial, qual seria a contribuição da pesquisa e das políticas públicas para a promoção da saúde? Esta foi a questão que nos colocamos, instigados pela Mesa - A pesquisa sobre impactos dos agrotóxicos e implicações para a proteção da saúde, organizada no Congresso Brasileiro de Epidemiologia - 2011 por iniciativa do GT Saúde e Ambiente da ABRASCO. Tomamos como ponto de partida a experiência do Estudo epidemiológico da população da região do Baixo Jaguaribe exposta à contaminação ambiental em área de uso de agrotóxicos, pesquisa realizada entre 2007 e 2011, com apoio do CNPq, na região do Baixo Jaguaribe no Ceará. Trata-se de zona de recente expansão agrícola, onde se implantaram grandes empresas transnacionais e nacionais a partir de 2000, para produzir e exportar frutas. Foram quatro anos de intenso aprendi- zado no território e na equipe interdisciplinar da pesquisa, registrado em livro, teses, dissertações e monografias ${ }^{2}$.

Refletir sobre esta trajetória e sistematizar sua contribuição para a promoção da saúde foi o desafio que a equipe acolheu e registra neste ensaio, que partiu das vulnerabilidades e danos desvendados no território estudado para pensar os desafios de promover a saúde daqueles sujeitos e de outros que vivem em contextos semelhantes. Nesse processo, é feita a pergunta: quem deve, pode e quer promover a saúde no campo hoje?, e foram eleitos prioritariamente os campos da ciência e das políticas públicas como focos de diálogo crítico.

Assim se configuraram sete "lições aprendidas", que são compartilhadas na perspectiva da permanente construção do direito à saúde, ao ambiente saudável e à vida digna.

\section{Lições aprendidas}

\section{Para além de um risco químico isolado, a relação agrotóxicos-saúde deve ser estudada no contexto da modernização agrícola conservadora}

A aproximação do campo empírico, com o desafio de realizar estudo epidemiológico em populações expostas a agrotóxicos, logo nos mostrou que demandaria mais que as tradicionais categorias do "risco", "fator de risco" e "exposição", oferecidas pela epidemiologia clássica: a contaminação poderia ocorrer tanto nos locais de trabalho como nos de moradia; havia diferentes modelos de produção em dinâmica transformação e interação; as comunidades traziam preocupações relevantes com a perda da terra, contaminação de compartimentos ambientais e problemas de saúde; indícios de práticas de manejo inadequadas e as poucas informações disponíveis sugeriam forte vulnerabilidade populacional e institucional, entre outros ${ }^{3}$.

Fomos buscar elementos para compreender este complexo cenário nos pressupostos da Ecologia Política dos Riscos ${ }^{4}$, da Justiça Ambiental ${ }^{5}$, nos conceitos de Des-re-territorialização $0^{6}$ e na Epidemiologia $\mathrm{Crítica}^{7}$. Ao longo da trajetória da pesquisa, no diálogo com o território e seus sujeitos, fomos compreendendo que a ideia de um contexto de risco acolheria melhor o que vínhamos observando, e o definimos enquanto: o conjunto de fixos e fluxos materiais e imateriais produzidos por forças econômicas, políticas e simbólicas, configuradas no modelo de desenvolvimento e veiculadas por instituições públicas e processos de produção que estruturam e modificam a vida social, 
conformando cenários distintos de vulnerabilidade socioambiental e inequidade, os quais espelham o processo saúde-doença nos territórios ${ }^{8}$.

Tal compreensão foi determinante no desenho metodológico da pesquisa, que associou ao estudo epidemiológico a caracterização e avaliação da contaminação ambiental, o estudo do contexto sócio-histórico e das alternativas para a promoção da saúde, avaliadas tanto no espaço das políticas públicas como nas comunidades de resistência ao modelo?.

Alguns aspectos deste complexo contexto de risco desvendados nos diferentes segmentos estudados - trabalhadores do agronegócio, agricultores familiares camponeses e comunidade agroecológica - são ilustrados a seguir, com base em Marinho ${ }^{8}$, Teixeira et al. ${ }^{10}$ e Ferreira et al. ${ }^{11}$.

Os trabalhadores do agronegócio estão expostos diariamente a elevados volumes de múltiplos agentes tóxicos para garantir a "saúde das frutas", mas não dispõem de informação acerca deles; são obrigados a re-entrar nas áreas de cultivo sem respeito ao tempo pós-pulverização, muitas vezes sem os equipamentos de segurança minimamente necessários, e sem a liberdade de recusar o trabalho inseguro, pouco protegidos pelo sindicato e acossados por relações hierárquicas autoritárias. Sabem que, na portaria da empresa, há um exército de força de trabalho reserva, e já não possuem mais a terra para trabalhar autonomamente.

Já os pequenos agricultores compõem um segmento heterogêneo, em que alguns se tornam "parceiros" das grandes empresas para ter delas a possibilidade de comercialização (que uma política pública poderia oferecer) e assim recebem a imposição de um pacote tecnológico que inclui os mesmos agrotóxicos, sem contar, entretanto, com o aporte técnico para proteger seus familiares ou seus poucos empregados. Outros produzem de forma independente da grande empresa, lutando para pagar a conta de energia referente à água que chega ao perímetro irrigado - dívida que já levou muitos a perderem a terra. Encontram no balcão das lojas agropecuárias a "assistência técnica" que a política pública também não faz chegar até eles, substituindo o Receituário Agronômico que a lei exige, mas não há quem fiscalize: são os que usam os produtos de classe toxicológica mais elevada. Se esta despesa já é elevada para eles, o gasto com proteção é absolutamente secundarizado.

As famílias destes trabalhadores e trabalhadoras, tendo as grandes empresas no entorno de suas comunidades, a partir do reordenamento territorial que aquelas impuseram, recebem os agrotóxicos por contiguidade entre suas casas e os locais de produção, pela água dos canais de irrigação que é a mesma oferecida pelo município aos moradores; pelo ar, quando vem o tempo da pulverização aérea; pelos alimentos contaminados; pelas roupas dos trabalhadores que, a despeito da proibição legal, vão ser lavadas em casa, ampliando a domiciliação de riscos. Some-se ainda a violência, agudamente expressa no assassinato de uma liderança comunitária que lutava contra a contaminação das águas, e o medo, componentes materiais e simbólicos da vulnerabilidade.

As famílias assentadas da reforma agrária e da comunidade em transição agroecológica veem suas vidas e seus projetos ameaçados pela força do agronegócio que as circunda e contamina, no primeiro caso, e as expulsa, no segundo, para dar lugar a um novo perímetro irrigado, a ser ocupado por empresas mundializadas, desconsiderando a cultura local e o território socialmente construído em consonância com o bioma caatinga.

A avaliação desta trajetória de produção de conhecimento aponta seu potencial para desvelar de forma mais adequada o processo saúdedoença em cada contexto sócio-histórico específico, possibilitando melhores respostas das políticas públicas e dos serviços de saúde.

\section{2. É necessário e urgente desvendar os agravos à saúde relacionados} aos agrotóxicos. Entretanto, considerando as dificuldades para sua identificação e registro, deve ser dada maior relevância à caracterização do risco e da vulnerabilidade em cada contexto socio-histórico, e isto deve ser suficiente para não postergar a ação de proteção da saúde

A Organização Mundial da Saúde ${ }^{12}$ estima que, para cada caso notificado de intoxicação por agrotóxicos, há 50 outros que não aparecem nas estatísticas. Pudemos ver, em nosso estudo empírico, que $54 \%$ dos pequenos agricultores examinados não procuram assistência médica quando apresentam sintomas agudos de intoxicação - e 43,3\% apresentava este relato em algum momento da vida $^{13}$. O quadro agrava-se no que diz respeito aos efeitos crônicos da exposição ocupacional ou ambiental aos agrotóxicos, menos conhecidos e mais desafiantes no estabelecimento dos nexos e relações, diante de casos de cânceres, alterações da reprodução, quadros neurológicos centrais e periféricos, hepatopatias ou doenças hematológicas, respiratórias, renais, entre outras.

Remetemos assim a um universo de cidadãos que ainda não receberam o diagnóstico e as condutas adequadas, não acessaram seus direitos 
previdenciários e trabalhistas, nem tiveram seu sofrimento a cumprir pelo menos o papel de alertar as autoridades e a sociedade através da visibilidade em indicadores de saúde-doença. Evidenciou-se a necessidade de facilitar o acesso aos serviços de saúde, considerando as especificidades dos espaços rurais; de capacitar os serviços para identificar e caracterizar a exposição ocupacional e ambiental; de estimular o desenvolvimento e universalizar o acesso à avaliação por biomarcadores; e de fomentar a produção de conhecimento sobre as exposições múltiplas e em baixas doses, já que muito raramente se encontra a exposição a apenas um ingrediente ativo ${ }^{14}$.

Entretanto, é preciso questionar a exigência de sucessivas provas quantitativas para que o risco seja reconhecido como problema. Sustentar o paradigma do "uso seguro" de agrotóxicos e a proteção em "valores máximos de resíduos" sem dispor de meios e condições para a fiscalização, monitoramento e controle é caminho para ampliar a vulnerabilidade das populações. Ainda que se consiga "medir", superando as barreiras técnicas e logísticas, nos deparamos com lógicas que consideram os compartimentos ambientais como estanques e dissociados da convivência humana, e com uma legislação que estabelece "níveis aceitáveis" - para quem?

Reconhecer a necessidade de desvendar os danos relacionados aos agrotóxicos, não significa reforçar a cultura positivista hegemônica que exige a geração de evidências sobre os agravos, sua frequência e sua relação com os agrotóxicos em cada território, para então justificar a proteção da saúde e a prevenção, como se observa no comportamento de setores empresariais e mesmo do Estado. Se a literatura científica já aponta a nocividade destes biocidas; não precisamos contar mortos e adoecidos para compreender que é necessário controlar o uso e superar o modelo químico-dependente de produção de alimentos. Em cada território singular, caracterizar a existência do risco - a extensão a e diversidade do uso, a fragilidade das práticas de manejo, a vulnerabilidade da população exposta já deveria ser rotina da territorialização em saúde, desencadeando as ações de vigilância.

3. O Estado tem tido significativa eficácia no apoio ao agronegócio e sua expansão, ao lado de também significativa ineficácia nas políticas sociais de garantia de direitos

O Estado moderno, especialmente nos países periféricos do capitalismo avançado, vem apresentando crescente subordinação à política econômica decidida transnacionalmente, tanto na escala nacional como regional e local, onde os governos competem entre si para transformar as suas cidades ou regiões em agente de competitividade muito para além da economia nacional, convertendo-se em nódulos de uma rede global de trocas e de sistemas produtivos transnacionais ${ }^{15}$.

No cenário estudado, estes elementos se manifestaram de forma intensa, como elenca Teixeira ${ }^{16}$ :

. Dos R\$ 120 bilhões investidos pelo governo no setor agrícola e pecuário em 2011, R \$ 100 bilhões destinaram-se aos grandes proprietários, volume $600 \%$ superior ao destinado à agricultura familiar, que envolve milhares de famílias ${ }^{17}$.

- Os estabelecimentos agropecuários com 1.000 ou mais hectares captaram 43,6\% dos recursos públicos, mesmo representando apenas $0,9 \%$ do total de estabelecimentos que obtiveram financiamento ${ }^{18}$.

- O governo federal isentou os agrotóxicos de cobrança de $100 \%$ do IPI (Decreto Federal $6.006 / 2006)^{19}$, do PIS/PASEP e de COFINS (Decreto Federal no $5.630 / 2005)^{20}$, reduziu em $60 \%$ a alíquota de cobrança do ICMS sobre os agrotóxicos (Convênio no 100/97), e vários governos estaduais elevaram esta redução a 100\%, como é o caso do Ceará (Decreto no 24.569/1997) ${ }^{21}$.

- A Receita Federal deixou de recolher R \$ 8,85 bilhões de reais em 2010, em função de isenções, redução de tarifas e alíquotas sobre produtos agropecuários, ocorridas a partir da edição das Leis no 10.925 e 11.051 , ambas de $2004^{22}$.

Esta breve lista exclui a disponibilização de infraestrutura como estradas, portos e aeroportos; o apoio tecnológico da Embrapa; o perdão de dívidas; a facilitação da articulação institucional e política, entre outros. Dessa forma, o Estado incentiva a expansão do agronegócio no campo e também a produção de impactos socioambientais dele decorrentes, instituindo a externalização dos seus custos e propagando a ideologia de responsabilização individual pelos riscos coletivos.

Por outro lado, o Estado tem tido enorme dificuldade em garantir os direitos e em fazer cumprir as legislações de proteção do trabalho, do ambiente e da saúde. O emprego, que é um dos fortes elementos simbólicos que busca legitimar a implantação das novas empresas é, na verdade, uma experiência de precarização, como a denunciada por trabalhadores de empresa transnacional, em greve em 2008, envolvendo a escassez e as péssimas condições sanitárias de bebedouros e sanitários, a não reposição de EPIs, a falta de manutenção das máquinas, o desrespeito ao período de reentrada após pulverização nas áreas, não aceitação de atestados médicos, entre outros:

[...] tem que levar comida feita de madrugada. A comida azeda, você faz a sua refeição no meio do 
campo. Você não tem água pra beber se não levar. (Trabalhador entrevistado)

Do ponto de vista ambiental, o Estado mostrou dificuldade para controlar (e taxar) a extração e o uso da água subterrânea pelo agronegócio, enquanto o número de poços profundos aumentava em $600 \%{ }^{23}$; não controla os agrotóxicos utilizados no estado, competência legal dos órgãos de ambiente e agricultura, favorecendo a utilização por trabalhadores de produtos já banidos mundialmente. Tais órgãos reconheceram publicamente não dispor de condições para monitorar a contaminação ambiental por agrotóxicos, conforme exige a legislação, questão grave no caso da água para consumo humano.

No campo da saúde, não foram identificadas ações de vigilância (sanitária, epidemiológica, em saúde do trabalhador ou ambiental) relacionadas aos agrotóxicos no sistema público local, mesmo com a formalização de denúncias e acionamento do Ministério Público. As unidades de saúde, além de não garantirem o acesso aos trabalhadores rurais, pelo horário de funcionamento, não consideram as especificidades dos processos produtivos instalados no território para planejar as ações, pautando suas práticas em programas verticais do Ministério da Saúde, desconhecendo os riscos introduzidos pela migração de trabalhadores ou pelas tecnologias adotadas nas "fábricas". Não há capacidade institucional instalada para o diagnóstico, tratamento e notificação dos casos de intoxicação aguda ou de efeitos crônicos. Na prática, após 20 anos de SUS, ainda há diversos processos descontínuos e dicotômicos na efetivação do cuidado à saúde a partir da compreensão do usuário como trabalhador e, portanto, submetido a relações, ambientes e processos de trabalho que contribuem para o aparecimento de doenças e acidentes de trabalho ${ }^{24}$.

Os sujeitos coletivos atuantes na área onde a pesquisa foi realizada percebem assim o papel do Estado:

[...] o Estado é na verdade dominado por uma elite, né? Então os interesses que estão lá não são da população em si. Essa elite está tendo lucro, ela está tendo a sua estabilidade financeira de status e de poder, então o Estado não se preocupa com aqueles que estão sofrendo, pessoas que estão excluídas do sistema, as pessoas que sofrem na pele mesmo os danos do agronegócio. O Estado está preocupado com o PIB, as exportações, a balança comercial, mas quanto ao bem-estar das pessoas, o Estado é negligente e omisso. [...] E a saúde da população e o meio ambiente ficam em segundo plano, ou a qualidade de vida das pessoas fica em segundo plano. Pelo que vejo, há uma posição estável, acho que desde o começo eles estavam a favor e continuam a favor do agronegócio (Entrevista com Cáritas Diocesana de Limoeiro do Norte).

As ações deste Estado, aparentemente ambíguo em sua eficiência/ineficiência, apontam, como vetor resultante, ser determinante como mediador e operador da vulnerabilização da população camponesa.

\section{Setores da sociedade ligados às organizações do campo veem desempenhando importante papel na política pública de combate aos agrotóxicos e de proteção da saúde}

A opção política do governo de legitimar a expansão do agronegócio tem gerado conflitos socioambientais e de saúde. As populações atingidas, desafiadas a lidar com problemas até então desconhecidos, têm denunciado os impactos desse modelo na expropriação das terras, proletarização em relações de trabalho precárias, degradação e contaminação ambiental, adoecimento das pessoas, desaparecimento e mudanças no modo de vida das comunidades camponesas, trazendo a público o "outro lado" do desenvolvimento no campo e questionando, com suas lutas, os níveis toleráveis de subordinação e exploração.

Foi assim que movimentos sociais do campo no Ceará levaram às organizações que compõem a Via Campesina no plano nacional, a questão dos agrotóxicos, enquanto expressão das mais sensíveis de todo este contexto. A preocupação encontrou eco e acolhida, levando à realização do Seminário Nacional Agrotóxicos, em setembro de 2010, onde foi deliberada a criação da Campanha Permanente contra os Agrotóxicos e pela Vida. No Dia Mundial da Saúde de 2011, ampla frente de movimentos sociais do campo e da cidade lançou a Campanha, coordenada por mais de vinte entidades nacionais como a Via Campesina, Central Única dos Trabalhadores (Cut), Articulação Nacional de Agroecologia (Ana) e o Fórum Brasileiro de Segurança e Soberania Alimentar e Nutricional (FBSSAN). Recebeu adesões de sociedades cientificas como a Associação Brasileira de Saúde Coletiva (Abrasco) e instituições públicas como a Fundação Oswaldo Cruz (Fiocruz) e o Instituto Nacional do Câncer (Inca). Além dessas entidades, outras vêm se somando em mais de 20 comitês estaduais no Brasil, além dos diversos comitês locais. Inicialmente focando a contaminação dos alimentos por agrotóxicos, produziram o documentário "O Veneno Está na Mesa" de Silvio Tendler, que tem possibilitado o debate das relações campo-cidade, ampliando o envolvimento dos consumidores de alimentos no de- 
bate do modelo de produção agrícola e pautando as políticas públicas pertinentes.

Estas, mesmo quando conquistadas na forma de direitos e leis, ainda demandam, para sua efetivação, o sobre-esforço da luta política ${ }^{25}$. Considerando o contexto em que o Estado, mais especificamente o SUS, tem exercido uma ação débil em termos da vigilância das populações expostas a agrotóxicos, a Campanha tem provocado o Governo Federal e o Legislativo, levando à criação de um grupo intersetorial de enfrentamento dos danos dos agrotóxicos no âmbito da Secretaria Geral da Presidência da República, entre outras ações.

A intensa mobilização da sociedade tem gerado a realização de audiências públicas, debates, produção e difusão ampliada de informações, proibição de pulverização aérea em alguns municípios, se constituindo em ações concretas que as políticas públicas de governo estavam sendo incapazes de realizar, e levando a reconhecer o importante papel de proteção da saúde pública desenvolvido por estes movimentos.

\section{Como a produção e a imposição de mitos é um dos sustentáculos simbólicos do atual modelo, é importante que os estudos contribuam também na identificação destes mitos e na sua desconstrução}

É possível legitimar esse modelo de desenvolvimento no campo sem a força de um discurso poderoso que desenhasse no imaginário dos diferentes segmentos sociais a promessa de progresso e desenvolvimento? Compreender este processo exige olhar cuidadosamente sobre as formas de dominação simbólica que o sustentam. Os mecanismos que atuam para garantir a reprodução de uma ordem social injusta, promotora da desigualdade e da degradação socioambiental são mais complexos do que poderia propor uma abordagem que contemplasse apenas as relações materiais de produção e reprodução do capital. Segundo Thompson ${ }^{26}$, para entender as relações de dominação simbólica é preciso analisar como palavras e imagens - compreendidas aqui como construções discursivas, são capazes de sustentar e reproduzir uma ordem social opressora e dificultar o caminho para transformações sociais.

No cotidiano do trabalho, das lutas e das tensões sociais presentes no território, se evidenciam as contradições do modelo de desenvolvimento que se reproduz atravessado por discursos dissonantes. De um lado a grande promessa, nunca cumprida às populações locais, de uma vida melhor. De outro, a realidade vivida pelas populações que pagam cotidianamente o preço da busca interminável pelo progresso. Bourdieu ${ }^{27}$ nos provoca sobre a importância de enveredarmos pelo campo da análise do poder simbólico:

[...] como poder de constituir o dado pela enunciação, de fazer ver e fazer crer, de confirmar ou de transformar a visão do mundo e, deste modo, a ação sobre o mundo, portanto o mundo, poder quase mágico que permite o equivalente daquilo que é obtido pela força (física ou econômica), graças ao efeito específico de mobilização, só se exerce se for reconhecido, quer dizer, ignorado como arbitrário ${ }^{27}$.

Desse modo, para desvelar as engrenagens de operação e produção simbólica foi utilizada a matriz discursiva da promessa do emprego, progresso e ascensão à modernidade que o agronegócio instalou na Chapada do Apodi. Os modos de vida e de produção existentes passaram a ser descritos como "arcaicos" e vários mitos foram construídos e replicados para justificar as diversas intervenções ocasionadas pelo modelo agrícola conservador que, mesmo carregando as mais atrasadas práticas, se reveste de "moderno" em seu discurso.

Barthes $^{28}$ nos adverte que a busca do mito é simplificar o mundo naturalizando-o, em outras palavras, a função do mito é retirar a história das coisas de modo a torná-las naturais. Esta "captura" da história das coisas promovida pelo mito mostrou-se útil para a legitimação do discurso desenvolvimentista na Chapada do Apodi.

Nesse contexto, tornou-se importante narrar o processo vivido pelas populações locais e as lições aprendidas na pesquisa como uma tentativa de devolver a história das coisas e desnaturalizar os significados dados. Diversas estratégias e materiais de comunicação como livro, cordel, cartazes, foram produzidos. Enfocaremos a experiência da construção do almanaque, que resultou na identificação de sete mitos legitimadores da expansão do agronegócio:

MITO 1: Não existia vida na Chapada do Apodi antes do agronegócio chegar.

MITO 2: O agronegócio é moderno e traz o progresso para nós: gera emprego e renda, produz alimentos para acabar com a fome no Brasil e potencializa a riqueza do país.

MITO 3: É possivel usar venenos com toda a segurança. Os pequenos agricultores é que são o problema! Nem usam os equipamentos de proteção. $O$ efeito do veneno é só no dia em que se pulveriza.

MITO 4: O agronegócio se preocupa com o meio ambiente.

MITO 5: O agronegócio promove o desenvolvimento local. 
MITO 6: Não há problemas com o uso de agrotóxicos, porque "as autoridades estão cuidando da gente".

MITO 7: Não existe outra forma de produzir que não seja a do agronegócio.

Ao recontar a história das coisas, o que o Almanaque busca é devolver-lhes a complexidade e tira-lhes o status de "naturais", revelando que ali existiam há séculos modos de viver e produzir próprios, que existem na região formas de produção agroecológicas, que o Estado está imbricado com a reprodução do capital, que os pequenos agricultores também são vítimas do discurso da Revolução Verde, a precarização das relações de trabalho e os agravos à saúde dos/as trabalhadores/as, os graves impactos ambientais, etc.

No exercício de contar e recontar a história das coisas - articulando a experiência daqueles que fazem o território com os elementos trazidos pela pesquisa e com a força de mobilização dos movimentos sociais -, é que se tornou possível apontar para a construção de novas "falas" sobre a realidade. Isso se coloca como relevante na medida em que conseguimos avançar na perspectiva proposta por Barthes ${ }^{28}$ quando diz que "é isso que devemos procurar: uma reconciliação entre o real e os homens, a descrição e a explicação, o objeto e o saber".

\section{Estamos diante do desafio de contribuir} na construção de ciência emancipatória, fundada no compromisso ético-político com os mais vulneráveis

São enormes os desafios contemporâneos à produção do conhecimento e ao campo científico. A ciência moderna, nascida nas sociedades ocidentais e datada na emergência histórica do projeto burguês de mundo, vem cumprindo o papel imprescindível de subsidiar o desenvolvimento da civilização do capital. Se muitos benefícios são frutos do sistema técnico-científico, junto com Haesbaert e Porto-Gonçalves ${ }^{29}$ reconhecemos que "a revolução tecnológica não é externa às relações sociais e de poder" e que "vivemos um mundo em que os maiores perigos já não mais advêm da peste ou da fome, mas, sim, das próprias intervenções feitas por meio deste mesmo sistema técnico-científico".

Mészáros ${ }^{30}$ caracteriza uma "crise histórica sem precedentes, estrutural, profunda, do próprio sistema do capital", constatamos o desenvolvimento do novo modelo de acumulação de capital, que não só trabalha mediante a extração de mais-valia e os tradicionais mecanismos de mercado, mas desenvolve práticas predatórias, a fraude e a extração violenta, aproveitando as de- sigualdades e as assimetrias entre os grupos sociais, para pilhar os recursos dos mais frágeis, produzindo injustiças e racismo ambiental ${ }^{31}$. Vivenciamos ainda a industrialização da ciência: a priorização de objetos de estudo que interessam ao mercado e são financiados por grandes grupos econômicos, a despeito das demandas de conhecimento de grupos sociais mais vulneráveis; à elaboração de pareceres com resultados previamente encomendados e acordados; a omissão da dúvida e da ignorância; e até mesmo as evidências de suspeitas na liberação dos transgênicos, entre outros.

Neste contexto, é necessário assumir nossas responsabilidades, enquanto campo científico, na produção da crise e da injusta sociedade de risco contemporâneas, bem como o enorme desafio ético e histórico de contribuir na construção de ciência emancipatória, rompendo com o "epistemicídio" posto pela ciência moderna ${ }^{32}$, em direção à "ecologia de saberes" que portem mais sabedoria ${ }^{33}$.

O diálogo se inicia na definição do objeto deste estudo, quando os movimentos sociais do campo confirmaram as indicações epidemiológicas de que haveria na região do baixo vale do Jaguaribe um contexto relevante de exposição aos agrotóxicos relacionando-o à expansão do agronegócio e compuseram a equipe da pesquisa, a Comissão Pastoral da Terra (CPT) e o MST. Dessa forma foi tecida a aproximação e a confiança entre nossa equipe e as comunidades atingidas permitindo-nos o contato com o saber popular e camponês, compreender o processo de desterritorialização na perspectiva dos atingidos, valorizando a horizontalidade e a solidariedade como forma de produção de conhecimento e constituindo, na própria pesquisa, um campo de formação recíproca.

Nele pudemos nos desafiar a experimentar novos papéis e processos de trabalho em pesquisa, articulando interdisciplinaridade e ecologia de saberes, fragmentos do real e sínteses em busca da totalidade; construção processual da metodologia, em diálogo com o campo empírico e seus sujeitos. Estabelecemos processos de comunicação permanentes com o território, ouvindo e compartilhando informações em Seminários abertos ao público, Oficinas, reuniões, boletins, audiências públicas, e entrevistas na mídia. Assim, a trajetória da pesquisa foi se articulando à trajetória das lutas populares e camponesas na região, ao emprestar o capital simbólico da Universidade e disponibilizar informações, cuja apropriação pelos movimentos sociais fortaleciam as ações em defesa da saúde e da vida.

Citamos aqui o envolvimento com a luta das comunidades contra a contaminação da água, 
onde a pesquisa pôde confirmar a presença de agrotóxicos na água e mostrar seus riscos e impactos à saúde humana, em audiências públicas na Câmara Municipal e na Assembleia Legislativa Estadual, culminando com a proibição da pulverização aérea no município; além da participação ativa no Movimento 21, surgido após o assassinato do líder comunitário “Zé Maria do Tomé”. Outro exemplo foi a elaboração de um dossiê sobre os seis mais relevantes problemas de saúde pública identificados na pesquisa, formalmente entregue às autoridades públicas em eventos abertos à participação.

Ao rompermos com a falsa neutralidade científica, que promove o distanciamento do sujeito que pesquisa com o objeto pesquisado, assumimos o desafio de contribuir para a construção de "uma ciência que vá ao mundo vivo recolher seus objetos de estudo, a partir das lentes da sensibilidade engajada, ao encontro daqueles que sofrem, dos grupos humanos e das classes sociais mais vulneráveis" 34 .

Não se trata de compreender que a pesquisa, por si só, tenha o papel de empoderar as classes menos favorecidas ou de transformar realidades. A nosso ver, a atividade teórica em si não é dotada dessa capacidade, pois carece de um objeto prático, ou seja, falta aqui o lado material, imanente ao sujeito das ações ${ }^{35}$. Para que a pesquisa se transforme em ação com vistas à emancipação social ela tem de ser ressignificada, vivificada pelos sujeitos sociais.

Colocar-se ao lado dos mais vulneráveis é uma postura ética que tem levado vários pesquisadores a ações judiciais de criminalização pelos grandes empreendedores, especialmente no campo dos impactos ambientais e à saúde humana. Dessa forma, é urgente pautar a necessidade de construção de mecanismos de abrigo institucional dos pesquisadores e de garantia da autonomia da atividade acadêmica em relação aos interesses econômicos.

\section{7 - Comunidades camponesas vêm construindo alternativas agroecológicas de vida no semiárido, a despeito da invisibilidade, do desamparo das políticas públicas e do encurralamento pelo agronegócio}

Há mais de 30 anos comunidades do Tabuleiro de Russas são protagonistas da construção de formas de organização comunitária para a convivência com o semiárido, em transição agroecológica, com atividades produtivas como agricultura, apicultura, pesca de subsistência, ovinocultura, extração de palha e óleo de carnaúba e coleta de castanha; viabilizando alternativas para a gestão das águas; cuidando das questões da juventude e da cultura. $\mathrm{O}$ vigor das iniciativas fez delas comunidades-modelo, visitadas por entidades nacionais e estrangeiras, inspirando outros grupos e criando relações inovadoras com as políticas públicas.

Entretanto, em 2007, tomaram conhecimento de que, a despeito da ausência de consulta ou informação à população local, suas terras haviam sido decretadas de utilidade pública para fins de desapropriação pelo Departamento Nacional de Obras Contra Secas. O objetivo era implantar a segunda etapa de um Perímetro Irrigado, onde as melhores terras seriam disponibilizadas às grandes empresas transnacionais da fruticultura, consolidando sua inserção para além da Chapada do Apodi ${ }^{36}$.

As casas e seus produtivos quintais, etnobiodiversos; a casa do mel, base da cooperativa de jovens apicultores; a casa de farinha, que presta serviço às comunidades vizinhas também; a casa de sementes, onde a biodiversidade e a autonomia dos camponeses são guardadas, nada disto é reconhecido pela política pública. Ao contrário, o Estudo de Impacto Ambiental, insiste na invisibilização da população ao argumentar, por exemplo, que o projeto trará baixo impacto ao meio antrópico pois “a população local é rarefeita e vive de uma economia pouco significativa devido à escassez de recursos hídricos, não sendo tão afetada com a desapropriação" 37 .

A negação e desqualificação do modo de vida tradicional em relação ao modelo da modernização agrícola aproxima-se do que vem sendo conceituado como racismo ambiental. Os argumentos apresentados no EIA sobre os benefícios para a população trazidos pelo projeto de irrigação só podem ser compreendidos enquanto retórica, face às evidências contrárias já fartamente divulgadas.

Discutindo o tema da construção de alternativas ao modelo de desenvolvimento hegemônico, em sua fragilidade e potencialidades, Santos e Rodrigues $^{38}$ enfatizam:

A insistência na viabilidade das alternativas não implica, contudo, uma aceitação do que existe. A afirmação fundamental do pensamento crítico consiste na asserção de que a realidade não se reduz ao que existe. A realidade é um campo de possibilidades em que têm cabimento alternativas que foram marginalizadas ou que nem sequer foram tentadas. Neste sentido, a função das práticas $e$ do pensamento emancipadores consiste em ampliar o espectro do possivel através da experimentação e da reflexão acerca de alternativas que re- 
presentem formas de sociedades mais justas. Ao apontar para além daquilo que existe, as referidas formas de pensamento e de prática põem em causa a separação entre realidade e utopia e formulam alternativas que são suficientemente reais para não serem facilmente descartadas por serem inviáveis.

Tais reflexões acolhem a perspectiva da Agroecologia, enquanto um conhecimento em construção no diálogo entre a ciência moderna e os saberes tradicionais, voltando-se não apenas para a dimensão da produção, mas considerando em outra cosmovisão as inter-relações entre a terraterritório-territorialidades em suas dimensões ecológicas, culturais, políticas, e éticas. Um paradigma que valoriza o conhecimento local e empírico dos agricultores, a socialização desse conhecimento e sua aplicação ao objetivo comum da sustentabilidade $e^{39}$.

A pesquisa revela a importância de contribuir para dar visibilidade aos conflitos do campo, fortalecendo os grupos atingidos pelo capital com a ajuda do Estado, cuja força vem sendo construída junto a redes sociais de entidades e organizações não-governamentais, pesquisadores e movimentos.

\section{Conclusões}

No campo da Saúde Coletiva, autores como Miranda ${ }^{1}$ questionam se "é possível economia verde para erradicação da miséria global, sem enfrentamento estrutural do capitalismo".

\section{Referências}

1. Miranda AC. O dilema da Rio +20 [editorial]. Cien Saude Colet 2012; 17(2):284.

2. Rigotto RM, organizadora. Agrotóxicos, trabalho e saúde: vulnerabilidade e resistência no contexto da modernização agrícola no Baixo Jaguaribe/CE. Fortaleza: UFC; 2011

3. Teixeira AAT, Marinho AMCP, Ellery AEL, Bezerra MGV, Rigotto RM, Ferreira MJM. Conceitos, olhares e primeiras interpretações sobre o problema em estudo. In: Rigotto RM, organizadora. Agrotóxicos, trabalho e saúde: vulnerabilidade e resistência no contexto da modernização agrícola no Baixo Jaguaribe/CE. Fortaleza: Edições UFC, Expressão Popular; 2011. p. 35-70.

4. Porto MF. Uma ecologia política dos riscos: princípios para integrarmos o local e o global na promoção da saúde e da justiça ambiental. Rio de Janeiro: Fiocruz; 2007.
Esse ensaio buscou dar resposta a essa indagação por meio da análise da relação agrotóxicos-saúde, que deve ser estudada no contexto da modernização agrícola conservadora, de forma a desvendar os agravos à saúde, o risco e a vulnerabilidade socioambiental, exigindo do Estado a implantação de políticas sociais de garantia de direitos. No atual contexto da Rio + 20 é fundamental que a sociedade civil cobre esse papel do Estado. É urgente o desenvolvimento de uma agenda de pesquisa que contribua na construção de uma ciência emancipatória, fundada no compromisso ético-político com os mais vulneráveis. É preciso buscar, como demonstram essas sete lições, formas críticas de fazer ciência, evidenciando os impactos do atual modelo de desenvolvimento na saúde, para abrir caminho para alternativas como a da Agroecologia, que contribuam para a construção de um mundo mais solidário e verdadeiramente sustentável.

\section{Colaboradores}

RM Rigotto, FF Carneiro, AMCP Marinho, MM Rocha, MJM Ferreira, VM Pessoa, ACA Teixeira, MLV Silva, LQV Braga e MM Teixeira participaram igualmente de todas as etapas de elaboração do artigo.
5. Acselrad H, Mello CCA, Bezerra GN. O que é Justiça Ambiental. Rio de Janeiro: Garamond; 2009.

6. Haesbaert R. O mito da desterritorialização: do "fim dos territórios" à multiterritorialidade. Rio de Janeiro: Bertrand Brasil; 2004

7. Breilh J. Epidemiologia Crítica: ciência emancipadora e interculturalidade. Rio de Janeiro: Editora Fiocruz; 2006.

8. Marinho AMCP. Contextos e contornos da modernização agrícola em municípios do Baixo Jaguaribe-CE: o espelho do (des)envolvimento e seus reflexos na saúde, trabalho e ambiente [tese]. São Paulo: Universidade de São Paulo; 2010.

9. Rigotto RM, Ellery AEL. Caminhos na produção do conhecimento: cuidados, incertezas e criação. In: Rigotto RM, organizadora. Agrotóxicos, trabalho e saúde: vulnerabilidade e resistência no contexto da modernização agrícola no Baixo Jaguaribe/CE. Fortaleza: Edições UFC, Expressão Popular; 2011. p. 71-110. 
10. Teixeira AAT, Marinho AMCP, Ferreira MJM, Rigotto RM, Braga LQV, Silva MLV. Tecendo aproximações entre o trabalho e a pluralidade a exposição dos trabalhadores a agrotóxicos e fertilizantes no Baixo Jaguaribe. In: Rigotto RM, organizadora. Agrotóxicos, trabalho e saúde: vulnerabilidade e resistência no contexto da modernização agrícola no Baixo Jaguaribe/CE. Fortaleza: Edições UFC, Expressão Popular; 2011. p. 319-360.

11. Ferreira MJM, Teixeira AAT, Marinho AMCP. Centralidade do trabalho e sua caracterização nos diferentes contextos de produção agrícola no Baixo Jaguaribe. In: Rigotto RM, organizadora. Agrotóxicos, trabalho e saúde: vulnerabilidade e resistência no contexto da modernização agrícola no Baixo Jaguaribe/CE. Fortaleza: Edições UFC, Expressão Popular; 2011. p. 296-318.

12. Organização Mundial da Saúde (OMS). Organização Pan-americana da Saúde (OPAS). Manual de Vigilância da Saúde de Populações Expostas a Agrotóxicos. Brasília: OPAS, OMS; 1996.

13. Maciel RHM, Rigotto RM, Alves PA. Como está a saúde destes trabalhadores? In: Rigotto RM, organizadora. Agrotóxicos, trabalho e saúde: vulnerabilidade e resistência no contexto da modernização agrícola no Baixo Jaguaribe/CE. Fortaleza: Edições UFC, Expressão Popular; 2011. p. 391-413.

14. Rosa IF, Pessoa VM, Rigotto RM. Introdução: agrotóxicos, saúde humana e os caminhos do estudo epidemiológico. In: Rigotto RM, organizadora. Agrotóxicos, Trabalho e Saúde: vulnerabilidade e resistência no contexto da modernização agrícola no Baixo Jaguaribe/CE. Fortaleza: Edições UFC, Expressão Popular; 2011. p. 217-256.

15. Santos BS. A gramática do tempo: para uma nova cultura política. 3. ed. São Paulo: Cortez; 2010.

16. Teixeira MM. "A criação do conflito foi que mostrou pra sociedade o quê que estava acontecendo ali": agronegócio, vida e trabalho no baixo Jaguaribe, CE [monografia]. Fortaleza: Universidade Federal do Ceará; 2010.

17. Brasil. Ministério da Agricultura, Pecuária e Abastecimento. Projeções do Agronegócio Brasil 2008/2009 a 2019/2020. 2. ed. Brasília: Ministério da Agricultura, Pecuária e Abastecimento; 2010.

18. Instituto Brasileiro de Geografia e Estatística (IBGE). Censo Agropecuário 2006. Rio de Janeiro: IBGE; 2009.

19. Brasil. Decreto no 6.006 , de 28 de dezembro de 2006. Aprova a Tabela de Incidência do Imposto sobre Produtos Industrializados - TIPI. Diário Oficial da União 2006; $29 \mathrm{dez}$.

20. Brasil. Decreto no 5.630 , de 22 de Dezembro de 2005. Dispõe sobre a redução a zero das alíquotas da Contribuição para o PIS/PASEP e da COFINS incidentes na importação e na comercialização no mercado interno de adubos, fertilizantes, defensivos agropecuários e outros produtos, de que trata o art. $1^{\circ}$ da Lei $n^{\circ} 10.925$, de 23 de julho de 2004. Diário Oficial da União 2005; 23 dez.

21. Ceará. Decreto no 24.569, de 31 de julho de 1997. Consolida e regulamenta a Legislação do Imposto Sobre Operações relativas à circulação de mercadorias e sobre prestações de serviços de transporte interestadual e intermunicipal e de comunicação (ICMS), e dá outras providências. Diário Oficial do Estado 1997; 4 ago.
22. Sauer S. Dinheiro Público para o agronegócio. Portal Diplomatique. [acessado 2010 nov 2]. Disponível em: http://diplomatique.uol.com.br/artigo.php?id $=654$

23. Companhia de Gestão dos Recursos Hídricos. Plano de gestão participativa dos aquíferos da bacia Potiguar, Estado do Ceará. Fortaleza: COGERH; 2009.

24. Pessoa VM. Abordagem do território na constituição da integralidade em saúde ambiental e saúde do trabalhador na atenção primária à saúde em Quixeré-Ceará [dissertação]. Fortaleza: Universidade Federal do Ceará; 2010.

25. Warren IS. Redes de movimentos sociais. São Paulo: Edições Loyola; 1993.

26. Thompson JB. Ideologia e Cultura moderna: teoria social crítica na era dos meios de comunicação de massa. 8a . ed. Petrópolis: Vozes; 2009.

27. Bourdieu P. O Poder Simbólico. 11ª . ed. Rio de Janeiro: Bertrand Brasil; 2007.

28. Barthes R. Mitologias. $11^{\text {a }}$ ed. Rio de Janeiro: Bertrand Brasil; 2001.

29. Haesbaert R, Porto-Gonçalves CW. A nova des-ordem mundial. São Paulo: UNESP; 2006.

30. Mészáros I. A crise estrutural do capital. São Paulo: Boitempo; 2009.

31. Acselrad H, Herculano S, Pádua JA, organizadores. Justiça Ambiental e Cidadania. Rio de Janeiro: RelumeDumará, Fundação Ford; 2004. p. 9-22.

32. Santos BS. Um discurso sobre as Ciências. $7^{\text {a }}$ ed. São Paulo: Cortez; 2010.

33. Neto FUS. Bioética com o sentido de ética-da-vida: uma experiência educadora. Programa de Doutorado em Educação Brasileira [tese]. Fortaleza: Universidade Federal do Ceará; 2011.

34. Rigotto RM. Os conflitos entre o agronegócio e os direitos das populações: o papel do campo científico. Rev Pegada 2011; 12(1):123-140.

35. Vásquez AS. Filosofia da Práxis. Buenos Aires, São Paulo: Consejo Latinoamericano de Ciências Sociales-CLACSO, Expresão Popular; 2007.

36. Braga LQV, Silva MLV, Feitosa MP. Com a Palavra, Os Que Lutam: Os Movimentos de Resistência das Comunidades do Baixo Jaguaribe em Defesa da Terra, do Trabalho e de Modos de Vida. In: Rigotto RM, organizadora. Agrotóxicos, trabalho e saúde: Vulnerabilidade e Resistência no Contexto da Modernização Agrícola no Baixo Jaguaribe/CE. Fortaleza: Edições UFC, Expressão Popular; 2011. p. 445-488.

37. Braga LQV. Agronegócio Cercando Agroecologia: Modo de Vida e Conflito Sócio-ambiental em Comunidades Agrícolas de Tabuleiro de Russas, Ceará [dissertação]. Fortaleza: Universidade Federal do Ceará; 2011.

38. Santos BS, Rodriguez C. Para Ampliar o Cânone da Produção. In: Santos BS, organizador. Produzir para viver: Os caminhos da produção não capitalista. $2^{a}$ ed. Rio de Janeiro: Civilização Brasileira; 2005.

39. Gliessman SR. Agroecologia: Processos ecológicos em agricultura sustentável. Porto Alegre: UFRGS; 2000.

Artigo apresentado em 11/04/2012

Aprovado em 23/04/2012

Versão final apresentada em 02/05/2012 